\title{
Peningkatan Kompetensi Mekatronika Bagi Guru SMK Balikpapan
}

\author{
Qory Hidayati $^{1^{*}}$; Nur Yanti ${ }^{1}$; Nurwahidah Jamal ${ }^{1}$ \\ ${ }^{1}$ Politeknik Negeri Balikpapan \\ 1*E-mail : qory.hidayati@poltekba.ac.id
}

\begin{abstract}
Abstrak
Semakin besar tuntutan untuk membuat lulusan dengan keterampilan yang memadai, perlu disiapkan pengajar yang berkualitas, serta memliki ketrampilan yang baik. Salah satu ketrampilan yang perlu dimiliki oleh guru SMK bidang elektro, listik maupun otomasi adalah mekatronika. Berdasarkan analisis kebutuhan serta diskusi dengan mitra, teridentifikasi 3 (tiga) permasalahan pokok, yaitu: (1) Guru masih sering menggunakan metode ceramah, sehingga siswa menjadi pasif dan mengakibatkan rendahnya kompetensi siswa pada mata pelajaran mekatronika. (2) Kondisi sarana dan prasarana sekolah masih kurang memadai mengakibatkan minat dan motivasi siswa dalam mengikuti pembelajaran menjadi berkurang. (3) Pemanfaatan media pembelajaran mekatronika oleh guru yang kurang maksimal mengakibatkan kreativitas siswa dalam pemecahan masalah tidak muncul. Hasil survei tim pelaksana pengabdian ini, menemukan bahwa guru-guru SMK bidang teknik kota Balikpapan membutuhkan keterampilan mekatronika dalam menggunakan Programable Logic Controller (PLC) terkait membuat model, merancang program dan memprogramnya yang sesuai dengan kebutuhan proses belajar mengajarnya untuk mengatisipasi kemajuan teknologi di bidang kontrol. Berdasarkan permasalahan dilaksanakan suatu pelatihan Peningkatan Kompetensi Mekatronika Bagi Siswa SMK Balikpapan, keterampilan mengenai PLC. Hasil dari kegiatan yang dilaksanakan tersebut dapat dikesimpulan bahwa pelatihan keterampilan Programmable Logic Controller (PLC) mampu membuat model, merancang program dan memprogram sendiri sesuai dengan kebutuhan proses pembelajaran.
\end{abstract}

Kata Kunci: Kompetensi, elektro, mekatronika, PLC, guru SMK

\begin{abstract}
The greater the demands to make graduates with adequate skills, qualified instructors need to be prepared, as well as possessing good skills. One of the skills that need to be possessed by vocational school teachers in the fields of electricity, electricity and automation is mechatronics. Based on needs analysis and discussion with partners, 3 (three) main problems were identified, namely: (1) Teachers still often use the lecture method, so students become passive and result in low student competency in mechatronic subjects. (2) The condition of school facilities and infrastructure is still inadequate resulting in reduced interest and motivation of students in participating in learning. (3) The use of mechatronics learning media by teachers is less than optimal resulting in students' creativity in solving problems not appearing. The survey results of this community service implementation team found that Balikpapan vocational school teachers in engineering require mechatronics skills in using the Programable Logic Controller (PLC) related to making models, designing programs and programming them according to the needs of the teaching and learning process to anticipate technological progress in the field of control . Based on the problem, a Mechatronics Competency Enhancement training for Balikpapan Vocational Students was held, regarding PLC skills. The results of the activities carried out can be drawn several conclusions, among them (1) community service activities carried out in the form of Programable Logic Controller (PLC) skills training to be able to make models, design programs and program their own PLCs according to the learning process needs, (2) This activity was carried out on July 25-27 2019 with representatives from 5 Vocational High Schools in the city of Balikpapan.
\end{abstract}

Keywords: Competence, electro, mechatronics, PLC, vocational teacher

\section{Pendahuluan}

Sekolah Menengah Kejuruan (SMK) merupakan pendidikan pada jenjang menengah yang mengutamakan pengembangan keterampilan dan kreativitas siswa. Sehubungan dengan hal tersebut hendaknya pendidikan berorientasi pada pengembangan kreativitas siswa agar kelak dapat

Volume 1, Nomor 2, 2019

ISSN 2657-1439 (Print), ISSN 2684-7043 (Online) diterapkan pada kehidupan pribadi, masyarakat, dan negara. Siswa perlu terbiasa berpikir kreatif agar dapat menyelesaikan suatu masalah pada saat mengikuti proses belajar mengajar mata pelajaran Mekatronika dengan sudut pandang yang berbeda.

Sebagian SMK di Balikpapan merupakan salah satu SMK yang menerapkan konsep pembelajaran 
teaching factory. Dalam roadmap pengembangan SMK 2010-2014 (Direktorat PSMK, 2009), teaching factory adalah gabungan dari pendekatan pembelajaran berbasis kompetensi dan pembelajaran berbasis produksi. Konsep pembelajaran ini menuntut siswa terbiasa dalam pemecahan masalah.

Mata pelajaran mekatronika merupakan salah satu mata pelajaran kejuruan di program Teknik Elektro maupun Teknik Listrik di SMK Balikpapan yang melatih keterampilan. Standar kompetensi pada mata pelajaran ini adalah menerapkan sistem PLC (Bolton, 2004). Dalam kegiatan pembelajaran siswa akan mempelajari tiga kompetensi dasar, yaitu perangkat keras, bahasa pemrograman dan aplikasi pemrograman.

Berdasarkan observasi awal SMK di Balikpapan, menunjukkan bahwa suasana proses pembelajaran didalam kelas masih sering menggunakan metode ceramah sehingga guru terkesan mendominasi aktivitas di kelas dan menimbulkan komunikasi satu arah dari guru ke siswa. Oleh sebab itu, dari hasil analisis situasi sebagaimana yang telah dipaparkan di atas, maka perlu dilakukan pembekalan pengetahuan/keterampilan kepada guru-guru SMK Balikpapan tentang pembuatan media pembelajaran. Adapun media pembelajaran yang akan di buat pelatihan pada guru-guru SMK di Balikpapan yang mengajar mata pelajaran mekatronika maupun PLC.

\section{Bahan dan Metode}

Kegiatan ini dilaksanakan dengan menggunakan pendekatan metode diskusi, ceramah, demonstrasi, praktik langsung, serta observasi. Dapat terlihat pada Gambar 1.

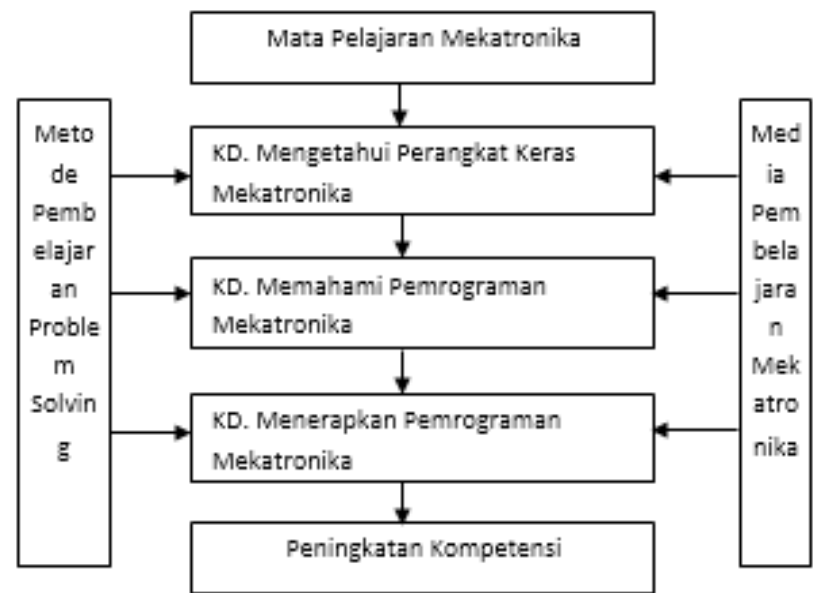

\section{Gambar 1 Diagram Blok Metode Pelaksanaan}

Proses pembelajaran menjadi suatu hal yang penting dalam tercapainya tujuan pembelajaran yang berakhir pada pencapaian hasil belajar siswa yang mencakup aspek kognitif, afektif dan psikomotorik.
Salah satu faktor yang dominan mempengaruhi hasil belahar di lingungan sekolah adalah metode guru dalam mengajar. Pembelajaran akan optimal apabia dilakukan dengan menggunakan metode mengajar yang tepat.

Pembelajaran diterapkan pada mata pelajaran mekatronika di rata-rata SMK masih menerapkan metode ceramah dan demonstrasi . Pemilihan metode ceramah dan demonstrasi dalam pembelajaran mekatronika tidaklah sepenuhnya salah, hanya saja dalam pelaksanaan nya guru kurang maksimal menggunakan metode tersebut, sehingga bersifat teacher centered dan tidak ada variasi dalam pembelajaran.

Berdasarkan analisis kebutuhan terhadap hasil penelitian yang terkait, juga diskusi dengan mitra, teridentifikasi permasalahan pokok, yaitu: (1) Masalah Praktikum PLC, (2) Masalah Kompetensi Guru. Dari setiap permasalahan tersebut adapun uraian tugas dari tim pengusul ialah dengan mempersiapkan perangkat praktikum Mekatronika termasuk trainer dan modul, dan kemudian dilakukan pelatihan terkait implementasi hardware dan software dengan simulasi langsung pada PLC (Artono, 2007). Selanjutnya dapat menggunakan PLC-Micro untuk menintegrasikan mata pelajaran PLC dan mikrokontroler (Hidayati, 2017).

\section{Hasil dan Pembahasan}

Pelaksanaan kegiatan pelatihan keterampilan Programmable Logic Controller (PLC) bagi guru SMK kota Balikpapan dapat berjalan dengan baik dan lancar. Hal ini diperoleh berkat kerjasama serta partisipasi aktif dan rasa pengabdian yang tinggi dari tim pelaksana, ditambah lagi dengan kerjasama dari semua pihak yang terkait dengan pelaksanaan kegiatan ini.

Pelaksanaan kegiatan ini diharapkan bisa membantu para guru dalam meningkatkan pengetahuannya mengenai PLC (Barrett, 2008)., terutama mengenai teknik pemograman dan aplikasinya.

Kegiatan pengabdian ini diikuti oleh 16 peserta, dari 5 Sekolah Menengah Kejuruan di Kota Balikpapan. pencapaian hasil pelaksanaan kegiatan pelatihan keterampilan Programmable Logic Controller (PLC) bagi guru SMK kota Balikpapan ini selanjutnya akan dilihat dari aspek tujuan dan manfaat pelaksanaan kegiatan. Berikut ini gambaran yang jelas tentang kegiatan yang telah dilaksanakan. 1. Pencapaian Tujuan. Secara umum tujuan yang telah ditetapkan sebelurnnya terjadi peningkatan kompetensi kemampuan guru-guru SMK bidang Teknik Kota Balikpapan agar terarnpil menggunakan Programable Logic Controller - PLC mulai dari membuat model, merancang program dan membuat programnya sesuai dengan kebutuhan proses belajar-mengajar yang 
diselaraskan dengan kemajuan teknologi udah terlaksana dengan baik menurut semestinya. 2. Pencapaian Target. Target dari pelaksanaan kegiatan ini adalah memberikan kegiatan pengabdian kepada masyarakat yakni; (1) meningkatkan pengetahuan guru SMK Kota Balikpapan mengenai PLC, (2) meningkatkan kemampuan guru SMK Kota Balikpapan mengenai pembuatan model untuk aplikasi PLC, (3) meningkatkan pengetahuan guru SMK Kota Balikpapan mengenai perancangan program untuk aplikasi PLC, (4) meningkatkan pengetahuan guru SMK Kota Balikpapan mengenai Pemograman PLC yang sesuai dengan kebutuhan proses pembelajaran.

Hasil yang telah dicapai adalah sebagai berikut:

1. Sesi I : Materi: Mengenal catu daya, peralatan sensor dan aktuator, serta cara merakitnya, logika NOT, AND, OR dalam rangkaian listrik (tanpa PLC) yang melibatkan catu daya, tombol, dan lampu. Aktivitas peserta: merangkai catu daya, tombol, dan lampu untuk membuktikan 4 rangkaian. Hasil: seluruh peserta mampu membuat semua logika rangkaian listrik pada perangkat pelatihan yang disediakan, dengan waktu yang bervariasi antar peserta.

2. Sesi II: Materi: Konsep PLC, Perubahan rangkaian listrik saat menggunakan PLC, dasar Ladder Diagram, mempraktikkan logika NOT, AND, OR dengan menggunakan PLC, menyelesaikan permalasahan-permasalahan paralel. Aktivitas peserta: menyesuaikan rangkaian catu daya, tombol, dan lampu yang telah dipelajari pada pertemuan pertama menjadi rangkaian yang lebih sederhana saat memanfaatkan PLC, mempelajari bahasa pemrograman Ladder Diagram khususnya tentang Rung, Contact, dan Coil, mempraktikkan logika NOT, AND, OR dengan menggunakan PL. Hasil: seluruh kelompok mampu mempraktikkan logika NOT, AND, OR dengan menggunakan PLC, dengan waktu yang bervariasi antar peserta.

3. Sesi III: Materi: membaca status output, Latch dan Lock, diagram notasi, program sekuensial, aplikasi sekuensial pada peralatan input. Aktivitas peserta: membuat program untuk membaca status output dan membuatnya sebagai bagian dari kondisi,membuat program untuk memanfaatkan flag sebagai jembatan antara input dan output, praktik Latch dan Lock serderhana, seperti pada Gambar 5.1.

4. Sesi IV: Materi: Pemantapan program sekuensial. Aktivitas peserta: melanjutkan tantangan hari ketiga, serta demonstrasi alat pemilah logam dan logam, penutupan pelatihan. Hasil: untuk seluruh aktivitas tugas yang diberikan ke peserta berhasil menyelesaikannya.

3. Pencapaian Manfaat.

Seperti yang telah dijelaskan pada bagian terdahulu bahwa manfaat dari kegiatan ini adalah Sesuai dengan tujuan yang telah dikemukakan, maka manfaat yang diharapkan dan dirasakan langsung oleh guru SMK
Kota Balikpapan adalah (1) peningkatan pengetahuan dan keterampilan dalam komputerisasi menggunakan PLC untuk kebutuhan proses pembelajaran di sekolah bidang teknik, (2) staf akademika Politeknik Negeri Balikpapan, khususnya jurusan Teknik Elektro Politeknik Negeri Balikpapan memperlihatkan peran aktifnya dalam memecahkan persoalan-persoalan yang ada dalam masyarakat terutama dalam penerapan ilrnu dan teknologi, khususnya pengetahuan tentang Programable Logic Controller (PLC) dan aplikasinya. Tahapan jangka panjang diharapkan kepada guru SMK Kota Balikpapan yang telah dilatih dapat menuangkan pengetahuan dan keterarnpilannya dalam proses belajar mengajar untuk meningkatkan mutu lulusannya.

\subsection{Implementasi Pemrograman}

Pelatihan ini direncanakan dilakasanakan selama 3 kali pertemuan dimana pertemuan dilaksanakan selama $8 \mathrm{jam} / \mathrm{hari}$. Pelatihan ini bertujuan untuk :

a. Memberi tahu cara pengoprasiannya.

b. Mengatahui membuat ladder diagram.

c. Mengetahui bila terjadi kesalahan PLC

Dalam menganalisa rancangan implementasi PLC dilakukan dengan menguji tiap-tiap bagian input dan output rangkaian untuk mendapatkan hasil apakah alat yang telah dirancang sesuai dengan yang diharapkan (Guo, 2009). Pengujian alat dilakukan untuk memastikan bahwa alat yang telah dibuat berfungsi dengan baik dan dapat digunakan.

\subsection{Faktor Pendukung dan penghambat}

Pelaksanaan kegiatan Pelatihan Keterampilan Programable Logic Controler (PLC) bagi guru-guru SMK Kota Balikpapan telah terlaksana sesuai tujuan dengan baik dan lancar. Selajutnya perlu dikaji dan dibahas faktor-faktor penentu keberhasilan pelaksanaan dan hambatannya. Ini dapat dilihat dari analisis pencapaian tujuan, pencpaian target dan manfaat, selajutnya juga dilihat dari beberapa faktor penentunya yang terdiri dari faktor pendorong tentang keberhasilan kegiatan ini, disarnping itu dibahas juga faktor yang menghambatnya.

\section{Faktor Pendorong}

Faktor pendorong yang dimaksud dalam pembahasan ini adalah faktor yang menunjang terhadap keberhasilan pelaksanaan kegiatan Pelatihan Keterarnpilan Programable Logic Controler (PLC) bagi guru-guru SMK Kota Balikpapan dalam bentuk pembuatan model, merancang program, dan mamprograrnnya sesuai dengan kebutuhan proses belajar mengajar dan mengantisipasi kemajuan teknologi di bidang kontrol . Adapun faktor-faktor yang menunjang pelaksanaan kegiatan ini dapat dikemukakan sebagai berikut:

a. Faktor Situasi kegiatan.

Oleh karena kegiatan ini memang berdasarkan kebutuhan dari masyarakat (Guru SMK Kota 
Balikpapan), maka dalam ha1 persiapan dan pelaksanaan kegiatan tidak menemui hambatan dan rintangan yang berarti, pelaksanaan dilaksanakan di Laboratoriurn kendali Jurusan Teknik Elektro Politeknik Negeri Balikpapan. Sehingga memudahkan bagi tim pelaksana membuat perencanaan, pelaksanaan pelatihan dan bimbingan.

\section{b. Masyarakat (sasaran).}

Semua peserta yang merupakan Guru-guru SMK Kota Balikpapan bidang teknik berperan serta aktif dari awal sarnpai akhir kegiatan pelatihan. Hal ini mungkin disebabkan bahwa kegiatan ini memang benar-benar dibutuhkan oleh khalayak sasaran.

\section{Faktor Pengharnbat}

Faktor penghambat dalam kegiatan pengabdian kepada masyarakat ini boleh dikatakan tidak ada. Adapun materi yang ditempuh adalah dengan mengkonsensuskan secara jelas terhadap materi latihan yakni memberikan pelatihan Peningkatan keterampilan PLC mulai dari membuat model, merancang program dan memprogramnya sesuai dengan kebutuhan proses pembelajaran. Oleh karena itu, selama kegiatan berlangsung tim pelaksana tidak mendapatkan hambatan yang berarti.

\subsection{Evaluasi}

Berdasarkan hasil angket yang telah diisi oleh 16 peserta, didapatkan hasil angket pada Tabel 1 .

\section{Tabel 1.}

Jadwal Pelaksanaan Pelatihan Mekatronika

\begin{tabular}{|c|c|c|c|c|c|}
\hline No & Pernyataan & SS & $\mathrm{S}$ & TS & STS \\
\hline 1 & $\begin{array}{l}\text { Materi dapat menambah } \\
\text { wawasan tentang } \\
\text { penggunaan Programmable } \\
\text { Logic Controller (PLC) }\end{array}$ & $75 \%$ & $25 \%$ & & \\
\hline 2 & $\begin{array}{l}\text { Materi disajikan secara } \\
\text { interaktif }\end{array}$ & $67 \%$ & $33 \%$ & & \\
\hline 3 & $\begin{array}{l}\text { Pelatihan dapat } \\
\text { meningkatkan keterampilan } \\
\text { dan kemampuan penggunaan } \\
\text { Programmable Logic } \\
\text { Controller (PLC) }\end{array}$ & $83 \%$ & $17 \%$ & & \\
\hline 4 & $\begin{array}{l}\text { Tim penyaji menyampaikan } \\
\text { materi dengan jelas }\end{array}$ & $75 \%$ & $25 \%$ & & \\
\hline 5 & $\begin{array}{l}\text { Tim penyaji mampu } \\
\text { membangun suasana belajar } \\
\text { yang baik }\end{array}$ & $75 \%$ & $25 \%$ & & \\
\hline 6 & $\begin{array}{l}\text { Pelatihan menggunakan } \\
\text { sarana yang mendukung } \\
\text { proses pembelajaran }\end{array}$ & $67 \%$ & $33 \%$ & & \\
\hline 7 & $\begin{array}{l}\text { Pelayanan konsumsi sudah } \\
\text { memadai }\end{array}$ & $42 \%$ & $58 \%$ & & \\
\hline 8 & $\begin{array}{l}\text { Pelatihan dapat } \\
\text { meningkatkan kemampuan } \\
\text { individu dan kelompok }\end{array}$ & $67 \%$ & $33 \%$ & & \\
\hline 9 & $\begin{array}{l}\text { Perlu diadakan pelatihan } \\
\text { lanjutan untuk pendalaman } \\
\text { materi Programmable Logic } \\
\text { Controller (PLC) }\end{array}$ & $92 \%$ & $8 \%$ & & \\
\hline
\end{tabular}

Keterangan: SS: jika Sangat Setuju, S: jika Setuju, TS: jika Tidak Setuju, STS: jika Sangat Tidak Setuju

Kesimpulan: dari 9 pernyataan angket terdapat 8 pernyataan mendapat respon sangat baik, dan 1 pernyataan hanya mendapat respon baik.

Volume 1, Nomor 1, 2019

ISSN 2657-1439 (Print), ISSN 2684-7043 (Online)

\section{Kesimpulan dan Saran}

Kegiatan pengabdian kepada masyarakat yang dilaksanakan berupa pelatihan mekatronika untuk keterampilan Programable Logic Controller (PLC) agar mampu membuat model, merancang program dan memprogram sendiri PLC sesuai dengan kebutuhan proses pembelajaran.

Kegiatan ini dilaksanakan pada tanggal 25 27 Juli 2019 dengan 5 perwakilan Sekolah Menengah Kejuruan di Kota Balikpapan yang memiliki Jurusan Teknik Elektro.

Materi yang telah disampaikan adalah: Dasar Logika Komputasi (NOT, AND, OR), Rangkaian Listrik Sederhana, Konsep PLC, Sensor, dan Aktuator, Fungsi Logika PLC, dan Kontrol Sekuensial Input. Setelah dilakukan pengamatan, indikator keberhasilan yang telah dicapai dalam pelatihan ini, adalah Peserta memahami materi yang diberikan, Peserta mampu menyelesaikan latihan yang ada di dalam modul, dan Peserta antusias meminta pelatihan lanjutan. Berdasarkan tanggapan, respon, dan partisipasi dari peserta dapat diambil kesimpulan bahwa peserta merasa puas atas kegiatan yang diselenggarakan dan berharap akan adanya pelatihan lanjutan.

\section{Ucapan Terima Kasih}

Penulis ingin mengucapkan terima kasih kepada P3M Politeknik Negeri Balikpapan yang telah dukungan terhadap pelaksanaan pengabdian kepada masyarakat dan kepada Guru - guru SMK kota Balikpapan atas partisipasi dalam mensukseskan pengabdian kepada masyarakat ini.

\section{Daftar Rujukan}

Bolton, W. (2004). Programmable Logic Controller (PLC), alih bahasa oleh: Irzam Harmeni, edisi ketiga, Penerbit Erlangga.

Hidayati, Qory. (2017). Desain Model dan Simulasi PLC-Mikrokontroler sebagai Modul Pembelajaran Berbasis PLC. JTERA - Jurnal Teknologi Rekayasa, 2(2), 73-82

Gumilar, G., Suhendi, A., \& Khairurrijal (2007). Rancang Bangun Programable Logic Controller Minimum berbasis Mikrokontroler ATMEL AT89S52", Jurnal PLC Berbasis Mikrokontroler, Institut Teknologi Bandung

Artono. (2007). Simulasi Sistem Kontrol Berbasis PLC, Seminar Nasional III SDM Teknologi Nuklir, Yogyakarta. 
Barrett, M. (2008). The Design Of A Portable Programmable Logic Controller (PLC) Training System For Use Outside Of The Automation Laboratory. International Symposium For Engineering Education. Ireland.

Guo, L. (2009). Design Projects in a Programmable Logic Controller (PLC) Course in Electrical Engineering Technology. Technology Interface Journal, 10(1) 